\title{
Ensino Superior à Distância a Partir da Constituição Federal de 1988: Base Normativa do Ensino Híbrido
}

\author{
Distance Higher Education from the 1988 Federal Constitution: Normative Basis of Blended \\ Learning
}

\author{
Bernadete Lema Mazzafera*a; Danilo Del Arco ${ }^{a}$
}

\begin{abstract}
aUnopar, Programa de Pós-Graduação Stricto Sensu em Metodologias para o Ensino de Linguagens e suas Tecnologias. PR, Brasil. *E-mail: bernalema@gmail.com.
\end{abstract}

\begin{abstract}
Resumo
As regras para a educação brasileira estão na Carta Magna e na Lei de diretrizes e base da Educação Nacional ( ${ }^{\circ}$ 9.394/96). A base legislativa que trata da modalidade de ensino a distância são os artigos 80 e 81 da lei 9.394/96. Estes artigos são regulamentados por decretos e portarias. A partir do exposto questiona-se como a legislação brasileira regulamenta o ensino híbrido? Este estudo tem como objetivo abordar a evolução do ensino superior à distância e compreender a legislação que possibilita o ensino híbrido. Para responder ao objetivo proposto realizou-se uma revisão da legislação nacional após a Constituição Federal de 1988 (CF/88) tendo como base a hierarquia das normas disposta no artigo 59 da $\mathrm{CF} / 88$. Segundo o texto constitucional há uma hierarquia entre as normas jurídicas brasileiras, a Constituição Federal é a norma ápice, que deve ser respeitada pelas Leis Ordinárias criadas sob sua vigência e, consequentemente, os decretos que regulamentarem as Leis Ordinárias devem estar em consonância com estas, assim como as portarias que esclarecem os decretos devem estar em conformidade com estes, pois, nesta ordem, todas as normas, de forma hierárquica, estarão de acordo com a Constituição Federal. O Decreto que está em vigor regulamenta o artigo 80 da Lei 9.394/96 é o de n ${ }^{\circ} 9.057 / 2017$ e as últimas portarias publicadas pelo MEC sobre ensino a distância são a de nº 2.117 de 2019 e acrescenta-se a portaria $\mathrm{n}^{\circ} 343$ de 2020 (específica para os tempos de pandemia).
\end{abstract}

Palavras-chave: Ensino Superior. Legislação Brasileira. Educação a Distância.

\begin{abstract}
The rules for Brazilian education are in the Carta Magna and in the Law of guidelines and basis of National Education ( $n^{\circ} 9.394$ / 96). The legislative basis that deals with the distance learning modality are articles 80 and 81 of law 9.394 / 96 . These articles are regulated by decrees and ordinances. Based on the above, it is questioned how Brazilian legislation regulates blended learning? This study aims to address the evolution of higher education at a distance and understand the legislation that makes blended learning possible. In order to respond to the proposed objective, a review of national legislation was carried out after the Federal Constitution of 1988 (CF / 88) based on the hierarchy of rules set out in article 59 of $\mathrm{CF} / 88$. According to the constitutional text, there is a hierarchy among the Brazilian legal norms, the Federal Constitution is the apex norm, which must be respected by the Ordinary Laws created under its validity and, consequently, the decrees that regulate the Ordinary Laws must be in line with these, as well as the ordinances that clarify the decrees must be in conformity with them, because, in this order, all rules, hierarchically, will be in accordance with the Federal Constitution. The Decree that is in force regulating article 80 of Law 9.394 / 96 is No. 9.057 / 2017 and the latest ordinance published by the MEC on hybrid education is No. 2,117 of 2019 and No. 343 of 2020 (specific for pandemic times).
\end{abstract}

Keywords: Higher Education. Brazilian legislation. Distance Education.

\section{Introdução}

Após oito anos de vigência da CF/88 foi publicada a Lei infraconstitucional que regulamenta a Educação no Brasil. Lei esta que deve obedecer a Constituição Federal de 1988 em todos os seus artigos e com base neles traçar as diretrizes, metas, objetivos para uma educação acessível e de qualidade a toda a população. Em razão das recentes alterações legislativas que tratam da temática de ensino híbrido no Brasil. Este estudo tem como objetivo refletir sobre o ensino superior híbrido a partir da legislação brasileira. Apresenta-se no estudo os artigos da Constituição Federal que tratam do tema Educação. Aborda-se que no comando constitucional do artigo 214 houve a determinação que o legislador infraconstitucional elaborasse uma norma de diretrizes e bases da educação nacional.

Esta norma, traduziu-se na Lei no 9.394 de 1996 que, em seus artigos 80 e 81 traz, pela primeira vez, a regulamentação do ensino a distância no Brasil, ou seja, a partir da edição da Lei de Diretrizes e Bases da Educação Nacional, passa-se a ter a possibilidade de desenvolver, além do ensino presencial, um ensino a distância acessível a toda a população.

A Lei de Diretrizes e Bases da Educação Nacional, Lei $\mathrm{n}^{\circ} 4.024$, foi publicada em 20 de dezembro1961 promulgada pelo então Presidente da República João Goulart, portanto, anterior a Constituição Federal de 1988 (CF/88).

Com o advento da Carta Magna, publicada em 05 de outubro de1988, a Educação passou a ser tratada no Capítulo III, Seção I, nos artigos 205 a 214.

A atual Constituição da República dispõe no seu artigo 205 que a educação, direito de todos e dever do Estado e da família, será promovida e incentivada com a colaboração da 
sociedade, visando ao pleno desenvolvimento da pessoa, seu preparo para o exercício da cidadania e sua qualificação para o trabalho. O artigo constitucional descreve que a educação é um dever do Estado brasileiro que deve regulamentá-la.

$\mathrm{O}$ artigo 206 elenca um rol de princípios que norteiam o ensino no Brasil, o inciso II assevera: "liberdade de aprender, ensinar, pesquisar e divulgar o pensamento, a arte e o saber;". No artigo 207 o constituinte deu às Universidades autonomia didática-científica e destacou que "obedecerão ao princípio de indissociabilidade entre ensino, pesquisa e extensão." No artigo 208 tem-se um rol de garantias que o Estado deverá cumprir para assegurar ou efetivar a educação no Brasil, dentre eles tem o previsto no inciso V: "acesso aos níveis mais elevados do ensino, da pesquisa e da criação artística, segundo a capacidade de cada um;".

O artigo 209 da CF/88 evidencia que: "O ensino é livre à iniciativa privada, atendidas as seguintes condições: I cumprimento das normas gerais da educação nacional; II - autorização e avaliação de qualidade pelo Poder Público". Assim, as Instituições de Ensino Privadas deverão respeitar e fazer cumprir tanto as leis infraconstitucionais como as portarias editadas pelo Estado brasileiro que regulamentam a Educação.

Os artigos 210 a 213 descrevem os conteúdos mínimos a serem abordados no ensino fundamental até a organização entre União, Estados e Municípios para colaboração dos sistemas de ensino, bem como a distribuição ou aplicação de verbas e recursos que deverão ser destinadas para a Educação.

Por fim, o artigo 214 da CF/88 merece destaque, não por ser o último artigo do capítulo que trata da Educação na $\mathrm{CF} / 88$, mas por trazer expressamente uma ordem, qual seja, "A lei estabelecerá o plano nacional de educação". Neste trecho há uma determinação que o Congresso Nacional crie uma Lei para definir diretrizes, objetivos e metas para educação, no mesmo "caput" do artigo tem-se: "[...]desenvolvimento do ensino em seus diversos níveis, etapas e modalidades[...]".O artigo em comento é a base constitucional da Lei $\mathrm{n}^{\circ} 9.394$, de 20 de dezembro de 1996, pois é esta a lei que trata das diretrizes e bases da educação nacional exigida pelo constituinte. A partir do exposto questiona-se como a legislação brasileira regulamenta o ensino híbrido? Neste estudo parte-se da legislação da educação a distância $(\mathrm{EaD})$ para compreender o Ensino Híbrido do ponto de vista legislativo. Este estudo tem como objetivo abordar a evolução do ensino superior à distância e compreender e a legislação que possibilita o ensino híbrido.

\section{Material e Métodos}

Para responder ao objetivo proposto realizou-se uma interpretação da legislação nacional após a Constituição Federal de 1988 (BRASIL, 1988). Seguiu-se a hierarquia das normas, mencionada no artigo 59 da CF/88 (Figura 1). Segundo o texto constitucional há uma hierarquia entre as normas jurídicas brasileiras, a Constituição Federal é a norma ápice, que deve ser respeitada pelas Leis Ordinárias criadas sob sua vigência e, consequentemente, os decretos que regulamentarem as Leis Ordinárias devem estar em consonância com estas, assim como as portarias que esclarecem os decretos devem estar em conformidade com estes, pois, nesta ordem, todas as normas, de forma hierárquica, estarão de acordo com a Constituição Federal.

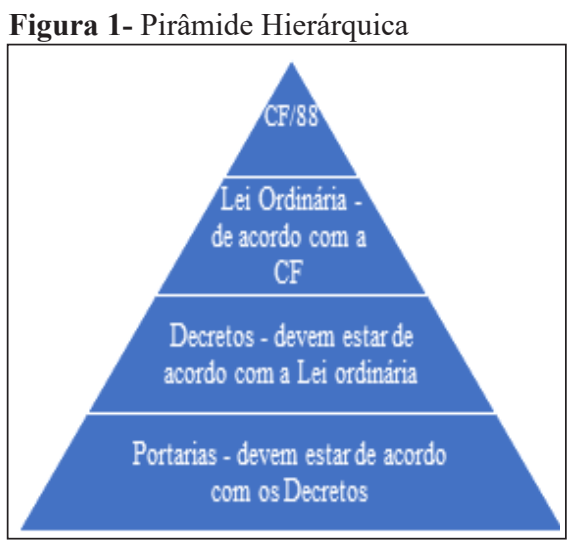

Fonte: Dados de pesquisa.

A busca por meio do google acadêmico foi realizada no período de março a abril de 2019 até abril de 2020 e conduziu para o site do Ministério da Educação, do Planalto e da Imprensa Nacional. Foram encontradas a Lei 9.394/96, legislação em vigor. Nesta lei encontram-se os artigos 80 e 81 que abordam o tema educação a distância, contudo, a abordagem é de forma genérica e abstrata, comum a toda legislação. Assim, as legislações mais densas e complexas, no Brasil possuem Decretos que as regulamentam. Dentre os decretos que foram editados após a $\mathrm{CF} / 88$ para esclarecer a aplicação dos artigos, e foi possível verificar o decreto 9.057/2017, último que foi editado e que se encontra em vigor. Após, foram realizadas interpretações das portarias que o Ministério da Educação (MEC) editou após a $\mathrm{CF} / 88$ que tratam especificamente de ensino a distância, que descrevem a forma de aplicação do artigo 81 da Lei 9.394/96. São seis portarias sobre o tema e a última portaria do MEC em vigor era a de $\mathrm{n}^{\mathrm{o}} 2.117$, de 06 de dezembro de 2019. Ressalta-se que em função da pandemia foi publicada em 18 de março de 2020 a portaria $n^{\circ} 343$ de 17 de março de 2020 que dispõe sobre a substituição das aulas "em meio digitais" enquanto durar a pandemia do novo corona vírus-COVID 19.

\section{Resultados e Discussão}

A Lei que estabelece as diretrizes e bases da educação nacional é a Lei 9.394 de 20 de dezembro de 1996 e em seu artigo $1^{\circ}, \S 2^{\circ}$ assevera que: “A educação escolar deverá vincular-se ao mundo do trabalho e à prática social." Esta foi a primeira e única legislação ordinária, infraconstitucional, após a Constituição Federal de 1998 que regulamentou a Educação no Brasil, obedecendo ao comando do artigo 214 da Carta 
Magna. O que comprova tal assertiva é que nos artigos $2^{\circ}$ e $3^{\circ}$ da respectiva Lei há praticamente uma repetição dos artigos 205 e 206 da CF/88. Ainda, após a publicação da mesma o Estado brasileiro apenas editou decretos e portarias para seu melhor esclarecimento e atualização.

Para este trabalho os artigos que se destacam na Lei 9.394/1996 são os artigos 80 e 81, pois ambos são rotineiramente utilizados como objetos de atualização e regulamentação por decretos e portarias. São eles:

Art. 80. O Poder Público incentivará o desenvolvimento e a veiculação de programas de ensino a distância, em todos os níveis e modalidades de ensino, e de educação continuada. § $1^{\circ}$ A educação a distância, organizada com abertura e regime especiais, será oferecida por instituições especificamente credenciadas pela União. $\S 2^{\circ}$ A União regulamentará os requisitos para a realização de exames e registro de diploma relativos a cursos de educação a distância. $\S 3^{\circ}$ As normas para produção, controle e avaliação de programas de educação a distância e a autorização para sua implementação, caberão aos respectivos sistemas de ensino, podendo haver cooperação e integração entre os diferentes sistemas. $\S 4^{\circ}$ A educação a distância gozará de tratamento diferenciado, que incluirá: I - custos de transmissão reduzidos em canais comerciais de radiodifusão sonora e de sons e imagens e em outros meios de comunicação que sejam explorados mediante autorização, concessão ou permissão do poder público; II - concessão de canais com finalidades exclusivamente educativas; III - reserva de tempo mínimo, sem ônus para o Poder Público, pelos concessionários de canais comerciais Art. 81. É permitida a organização de cursos ou instituições de ensino experimentais, desde que obedecidas as disposições desta Lei.

Pela primeira vez uma legislação brasileira reconhece e admite que a educação a distância deve ser implementada, incentivada e desenvolvida em todos os níveis e modalidades de ensino. Segundo Pillon, Freitas Filho e Misaghi (2018, p.29) “A Educação a Distância - EaD foi reconhecida oficialmente na Lei de Diretrizes e Bases da Educação Nacional (LDB), Lei Federal no 9.394, de 1996 [...]". Ainda, Moore e Kearsley (2008, apud PILLON; FREITAS FILHO; MISAGHI. 2018, p.29) afirmam que:

[...] a Educação a Distância caracteriza-se pelo fato de alunos e professores encontrarem-se em locais diferentes durante todo ou em grande parte do processo ensino-aprendizagem. Os autores enfatizam ainda que, estando em locais distintos, professores e alunos dependem de algum tipo de tecnologia necessária para transmitir as informações, como também para que seja possível a interação entre eles.

Desta forma, o legislador, ciente de que algum tipo de tecnologia deveria ser utilizado para auxiliar na mediação entre aluno e professor, trouxe no $\S 4^{\circ}$ do artigo 80 um tratamento diferenciado para a educação a distância, objetivou facilitar sua implementação. No artigo 81 o legislador autorizou a organização de cursos ou instituições de ensino experimentais, artigo este objeto de regulamentação de portarias do Ministério da Educação analisadas no estudo.

Torna-se relevante compreender os Decretos que regulamentaram o artigo 80 da Lei no 9.394/1996.

Diferentemente da Constituição Federal e da Lei 9.394 de
1996, que são editadas e publicadas pelo Congresso Nacional, os decretos que regulamentam a Lei 9.394/96 são editados e publicados pelo Governo Federal, na pessoa do Presidente da República, e retratam parte da sua política pública para a educação nacional.

Inicialmente, logo após a publicação e vigência da Lei 9.394/1996 foi publicado o Decreto ${ }^{\circ} 2.494$ de 10 de fevereiro de 1998 , e neste decreto, o seu artigo $1^{\circ}$ trouxe a primeira definição oficial de educação a distância no Brasil, segundo Santos (2011, p. 28): “O Decreto 2.494/98 definiu a EAD como uma modalidade de educação por autoaprendizagem, e que esta se realizaria pelo aluno a partir de estudos feitos com o apoio de recursos didáticos previamente estruturados". O artigo $1^{\circ}$ em seu parágrafo único traz:

Art. $1^{\circ}$ Educação a distância é uma forma de ensino que possibilita a autoaprendizagem, com a mediação de recursos didáticos sistematicamente organizados, apresentados em diferentes suportes de informação, utilizados isoladamente ou combinados, e veiculados pelos diversos meios de comunicação. Parágrafo Único - Os cursos ministrados sob a forma de educação a distância serão organizados em regime especial, com flexibilidade de requisitos para admissão, horários e duração, sem prejuízo, quando for o caso, dos objetivos e das diretrizes curriculares fixadas nacionalmente.

Contudo, no mesmo ano de 1998, em 27 de abril, o Decreto $n^{\circ} 2.494$ foi alterado em seus artigos 11 e 12 pelo Decreto $\mathrm{n}^{\circ} 2.561$, porém, em nada afetou a definição de ensino a distância. Assim, ambos os decretos vigoraram até o ano de 2005, quando foi publicado, em 19 de dezembro de 2005 o Decreto $\mathrm{n}^{\circ} 5.622$ que em seu artigo 37 revogou os decretos $n^{\circ}$ $2.494 / 98$ e $2.561 / 98$.

Este último decreto 5.622/2005 vigorou até 25 de maio de 2017, quando foi publicado o mais novo e atual Decreto (pelo então Presidente da República Michel Temer) que regulamenta o artigo 80 da Lei 9.394/1996, o Decreto $n^{\circ}$ 9.057/2017. Em seu artigo $1^{\circ}$ percebe-se uma ampliação do conceito de educação à distância, se compararmos com a definição dos decretos anteriores:

Para os fins deste Decreto, considera-se educação a distância a modalidade educacional na qual a mediação didáticopedagógica nos processos de ensino e aprendizagem ocorra com a utilização de meios e tecnologias de informação e comunicação, com pessoal qualificado, com políticas de acesso, com acompanhamento e avaliação compatíveis, entre outros, e desenvolva atividades educativas por estudantes e profissionais da educação que estejam em lugares e tempos diversos.

Assim, em termos de legislação de Ensino a Distância no Brasil tem-se o artigo 80 da Lei 9.394/1996 regulamentado pelo Decreto 9.057/2017. Todavia, o Ensino a distância no Brasil somente foi melhor esclarecido não em leis, mas sim em portarias editadas pelo Ministério da Educação.

\subsection{As Portarias do Ministério da Educação sobre Ensino a distância que possibilitam o Ensino Híbrido}

De forma diversa dos Decretos, que são editados e 
publicados pelo Presidente da República, as portarias do MEC são editadas e publicadas pelo Ministro da Educação, que traduz e ratifica parte da política pública do Governo Federal para a educação nacional.

Após a Constituição Federal de 1988 e a Lei 9.394/1996 a primeira portaria do Ministério da Educação a tratar do ensino a distância foi a Portaria $n^{\circ} 2.253$ de 18 de outubro de 2001, que autorizou a inclusão de disciplinas não presenciais em cursos superiores reconhecidos.

Todavia, antes de trazer o texto legal que embasou o ensino híbrido no Brasil, reputa-se destacar o Ensino Híbrido segundo Moran (2015, p.27):

Híbrido significa misturado, mesclado, blended. A educação sempre foi misturada, híbrida, sempre combinou vários espaços, tempos, atividades, metodologias, públicos. Esse processo, agora, com mobilidade e a conectividade, é muito mais perceptível, amplo e profundo: é um ecossistema mais aberto e criativo. Podemos ensinar e aprender de inúmeras formas, em todos os momentos, em múltiplos espaços. Híbrido é um conceito rico, apropriado e complicado. Tudo pode ser misturado, combinado, e podemos, com os mesmos ingredientes, preparar diversos "pratos", com sabores muito diferentes.

Observa-se que José Moran afirma que híbrido significa mistura, mas mistura do quê? No caso, ensino híbrido, seria a mistura do que há de melhor na educação presencial com o que há de melhor na educação a distância. Claro que esta mistura não é simples, segundo Moran (2015, p.27) “A mistura mais complexa é integrar o que vale a pena aprender, para e como fazê-lo".

Neste sentido foi publicado o parágrafo $1^{\circ}$ do artigo $1^{\circ}$ da Portaria 2.253/2001 que passou a admitir que 20\% (vinte por cento) das disciplinas integrantes do currículo de um curso presencial reconhecido fosse ministrada de maneira não presencial. Nesta acepção o curso de graduação é presencial com ofertas de disciplinas a distância.

Art. $1^{\circ}$ As instituições de ensino superior do sistema federal de ensino poderão introduzir, na organização pedagógica e curricular de seus cursos superiores reconhecidos, a oferta de disciplinas que, em seu todo ou em parte, utilizem método não presencial, com base no art. 81 da Lei no 9.394, de 1.996, e no disposto nesta Portaria. $\S 1^{\circ}$ As disciplinas a que se refere o caput, integrantes do currículo de cada curso superior reconhecido, não poderão exceder a vinte por cento do tempo previsto para integralização do respectivo currículo. (BRASIL, 2001, grifo nosso)

Esta portaria vigorou até a edição e publicação da Portaria $n^{\circ} 4.059$, de 10 de dezembro de 2004. Nesta segunda portaria, o Ministério da Educação manteve os $20 \%$ da carga horário total do curso (art. $1^{\circ}, \S 2^{\circ}$ ), mas alterou algumas denominações, como por exemplo, método não presencial passou a ser chamado de método semipresencial (art. $1^{\circ}$, caput) e foi atribuído um conceito de semipresencial (art. $1^{\circ}$, $\left.\S 1^{\circ}\right)$ :

Art. $1^{\circ}$. As instituições de ensino superior poderão introduzir, na organização pedagógica e curricular de seus cursos superiores reconhecidos, a oferta de disciplinas integrantes do currículo que utilizem modalidade semi-presencial, com base no art. 81 da Lei n. 9.394, de 1.996, e no disposto nesta Portaria. $\S 1^{\circ}$. Para fins desta Portaria, caracteriza-se a modalidade semi-presencial como quaisquer atividades didáticas, módulos ou unidades de ensino-aprendizagem centrados na auto-aprendizagem e com a mediação de recursos didáticos organizados em diferentes suportes de informação que utilizem tecnologias de comunicação remota. $\S 2^{\circ}$. Poderão ser ofertadas as disciplinas referidas no caput, integral ou parcialmente, desde que esta oferta não ultrapasse $20 \%$ (vinte por cento) da carga horária total do curso. (BRASIL, 2004) (grifo nosso)

Esta portaria esteve em vigor até a edição e publicação da Portaria $n^{\circ} 1.134$ de 10 de outubro de 2016, que revogou a Portaria do MEC n 4059, de 10 de dezembro de 2004, e estabeleceu nova redação para o tema. A principal alteração nesta portaria foi a desnecessidade da Instituição de Ensino Superior ter seus cursos reconhecidos para ofertar na organização dos mesmos a modalidade de disciplinas a distância. A partir desta portaria basta que a Instituição de Ensino Superior tenha um curso de graduação reconhecido para poder ofertar disciplinas a distância em todos os seus cursos de graduação, desde que estes cursos tenham regular autorização para funcionamento.

Assim, uma Universidade que tem cinco cursos de graduação, sendo quatro autorizados e apenas um reconhecido, poderá oferecer disciplinas a distância tanto no curso reconhecido como nos demais que são apenas autorizados, o que antes não se admitia, pois a portaria anterior exigia que para ofertar disciplina a distância o curso tivesse que ser reconhecido e não apenas autorizado.

Esta portaria manteve a oferta de $20 \%$ (vinte por cento) de disciplinas a distância nos cursos presenciais.

Art. $1^{\circ}$ As instituições de ensino superior que possuam pelo menos um curso de graduação reconhecido poderão introduzir, na organização pedagógica e curricular de seus cursos de graduação presenciais regularmente autorizados, a oferta de disciplinas na modalidade a distância. $\S 1^{\circ} \mathrm{As}$ disciplinas referidas no caput poderão ser ofertadas, integral ou parcialmente, desde que esta oferta não ultrapasse $20 \%$ (vinte por cento) da carga horária total do curso. (BRASIL, 2016, grifo nosso)

Em 28 de dezembro de 2018, o Ministério da Educação, na pessoa do então Ministro Rossieli Soares da Silva, editou a portaria $n^{\circ} 1.428$ e revogou a portaria $n^{\circ} 1.134 / 2016$. Inicialmente ficaram mantidas as regras da portaria anterior, ou seja, mantiveram os mesmos critérios para se ter no ensino presencial até $20 \%$ (vinte por cento) de disciplinas a distância. Porém, a grande inovação nesta atual portaria do MEC foi a possibilidade desses $20 \%$ serem ampliados para $40 \%$ (quarenta por cento) de disciplinas a distância na modalidade presencial, desde que alguns requisitos fossem cumpridos pela Instituição de Ensino Superior:

Art. $3^{\circ}$. O limite de $20 \%$ (vinte por cento) definido art. $2^{\circ}$ poderá ser ampliado para até $40 \%$ (quarenta por cento) para cursos de graduação presencial, desde que também atendidos os seguintes requisitos:

I - a IES deve estar credenciada em ambas as modalidades, 
presencial e a distância, com Conceito Institucional - CI igual ou superior a 4 (quatro);

I - a IES deve possuir um curso de graduação na modalidade a distância, com Conceito de Curso - CC igual ou superior a 4 (quatro), que tenha a mesma denominação e grau de um dos cursos de graduação presencial reconhecidos e ofertados pela IES;

III - os cursos de graduação presencial que poderão utilizar os limites definidos no caput devem ser reconhecidos, com Conceito de Curso - CC igual ou superior a 4 (quatro); e

IV - A IES não pode estar submetida a processo de supervisão, nos termos do Decreto no 9.235, de 2017, e da Portaria Normativa MEC no 315, de 4 de abril de 2018.

Art. $4^{\circ}$. As atividades pedagógicas e acadêmicas do curso presencial que ofertar disciplinas a distância, nos termos do art. $2^{\circ}$, devem ser realizadas exclusivamente na sede ou campi da IES.

Art. $6^{\circ}$. A possibilidade de ampliação da oferta de disciplinas na modalidade a distância, definida no art. $3^{\circ}$, não se aplica aos cursos de graduação presenciais da área de saúde e das engenharias. (BRASIL, 2018, grifo nosso).

Frisa-se que para as graduações na área de saúde e das engenharias esta possibilidade de ampliação para 40\% de disciplinas a distância na graduação presencial estava vedada.

Desta forma, atendidos os requisitos elencados nos quatro incisos do artigo $3^{\circ}$ da Portaria $n^{\circ} 1.428$, de 28 de dezembro de 2018, um curso de graduação presencial no Brasil hoje poderá ter até $40 \%$ do total da carga horária do curso ofertado em disciplinas a distância. No dia 06 de dezembro de 2019, o Ministério da Educação, na pessoa de seu Ministro Abraham Weintraub, publicou uma quinta portaria, a de número 2.117 de 2019, revogando, em seu artigo 10 , a portaria $n^{\circ} 1.428$ de 2018.

Nesta quinta e última portaria, ficou autorizado, em todos os cursos presenciais do país, com exceção apenas do curso de Medicina, a possibilidade de se ter até $40 \%$ da carga horária total do curso em modalidade EaD, sem precisar respeitar os requisitos dispostos na portaria anterior $n^{\circ} 1.428 / 2018$. O MEC avaliará se a IES faz esta oferta com a qualidade devida, sob pena de não ter o curso autorizado, como preconiza o disposto nos artigos $4^{\circ}, 6^{\circ}$ e $7^{\circ}$ da portaria 2.117/2019:

Art. $4^{\circ}$ A oferta de carga horária a distância em cursos presenciais deverá incluir métodos e práticas de ensinoaprendizagem que incorporem o uso integrado de Tecnologias de Informação e Comunicação - TIC para a realização dos objetivos pedagógicos, material didático específico bem como para a mediação de docentes, tutores e profissionais da educação com formação e qualificação em nível compatível com o previsto no PPC e no plano de ensino da disciplina.

Parágrafo único. O PPC deverá detalhar a forma de integralização da carga horária das disciplinas ofertadas parcial ou integralmente a distância, e o plano de ensino da disciplina deverá descrever as atividades realizadas.

Art. $6^{\circ}$ As IES devem informar no cadastro e-MEC a oferta de carga horária a distância para os cursos presenciais que venham a ser autorizados e aqueles já em funcionamento, cujo o projeto pedagógico contemple os termos dispostos nesta Portaria.

Art. $7^{\circ} \mathrm{Na}$ fase de Parecer Final dos processos de autorização de cursos presenciais, a possibilidade da oferta de carga horária a distância, até o limite de $40 \%$ da carga horária total do curso, além dos critérios estabelecidos pela Portaria
Normativa MEC $\mathrm{n}^{\circ} 20$, de 21 de dezembro de 2017, está sujeita à obtenção, pelo curso, de conceito igual ou superior a três em todos os indicadores a seguir:

I - Metodologia;

II - Atividades de tutoria;

III - Ambiente Virtual de Aprendizagem - AVA; e

IV - Tecnologias de Informação e Comunicação - TIC.

$\S 1^{\circ} \mathrm{O}$ não atendimento ao critério definido neste artigo ensejará o indeferimento do pedido de autorização do curso.

$\S 2^{\circ}$ Não serão permitidas alterações no PPC do curso, no âmbito do processo regulatório, após a realização da avaliação in loco. (BRASIL, 2019, grifo nosso)

$\mathrm{O}$ artigo $8^{\circ}$ da portaria exige o mesmo conceito igual ou superior a três para os processos de reconhecimento e renovação de cursos presenciais, o que demonstra que o MEC fará um controle da oferta desta modalidade EaD nos cursos presenciais:

Art. $8^{\circ} \mathrm{Na}$ fase de Parecer Final dos processos de reconhecimento e renovação de reconhecimento de cursos presenciais, será analisada a possibilidade de manutenção da oferta de carga horária a distância, até o limite de $40 \%$ da carga horária total do curso, se, além de atendidos os critérios estabelecidos pela Portaria Normativa MEC n 20, de 2017, o curso obtiver conceito igual ou superior a três em todos os indicadores a seguir:

I - Metodologia;

II - Atividades de tutoria;

III - Ambiente Virtual de Aprendizagem - AVA; e

IV - Tecnologias de Informação e Comunicação - TIC.

Parágrafo único. Nos casos em que não forem atendidos os critérios definidos neste artigo, caberá a aplicação dos procedimentos previstos pelos arts. 52 e seguintes do Decreto $\mathrm{n}^{\circ}$ 9.235, de 2017. (BRASIL, 2019, grifo nosso).

A partir da pandemia, o MEC publicou a portaria 343 de março de 2020 que dispõe sobre a substituição das aulas presenciais por aulas em meios digitais enquanto durar a situação de pandemia do Novo Coronavírus - COVID-19. No parágrafo $3^{\circ}$ explicita "Fica vedada a aplicação da substituição de que trata o caput aos cursos de Medicina bem como às práticas profissionais de estágios e de laboratório dos demais cursos" (BRASIL, 2020). Assim, manteve a proibição anterior ao curso de Medicina e práticas profissionais e estágios dos demais cursos.

\section{Conclusão}

As regras que norteiam a Educação no Brasil possuem sustentáculo na Carta Magna de 1988, com base nesta mesma Carta o legislador infraconstitucional elaborou e publicou a Lei de Diretrizes e Bases da Educação Nacional, Lei no 9.394 de 20 de dezembro de 1996. Nesta lei ordinária o legislador possibilitou o desenvolvimento da educação a distância no Brasil ao discorrer o disposto no seu artigo 80 e 81 . Para melhor esclarecer o disposto nos respectivos artigos os Presidentes da República, como base em suas políticas públicas, editaram decretos trazendo não somente o conceito de educação a distância, mas também como esta modalidade de ensino deverá se desenvolver junto às Instituições de Ensino no país. O Decreto que vigora atualmente, regulamentando o artigo 80 
da lei 9.394/96, é o de n ${ }^{\circ} 9.057$ de 25 de maio de 2017, editado pelo Ex-Presidente Michel Temer.

Para manter a política pública adotada pelo Governo Federal o Ministério da Educação (MEC), por meio do seu Ministro, edita portarias para melhor regulamentar alguns temas que não foram completamente esclarecidos no decreto, no caso deste trabalho, a Portaria do MEC que vigora sobre o tema ensino presencial e a distância, é Para manter a política pública adotada pelo Governo Federal o Ministério da Educação - MEC, por meio do seu Ministro, edita portarias para melhor regulamentar alguns temas que não foram completamente esclarecidos no decreto, no caso deste trabalho, a Portaria do MEC que vigora sobre o tema ensino híbrido, é a de no 2.117 de 06 de dezembro de 2019 , editada pelo então Ministro Abraham Weintraub.

Esta portaria trouxe uma inovação na oferta de disciplinas na modalidade a distância em cursos presenciais. Esta inovação está disposta no artigo $2^{\circ}$, caput e seus parágrafos, da referida portaria, que assevera que o limite de oferta de disciplinas na modalidade $\mathrm{EaD}$, em todos os cursos presenciais do país, com exceção do curso de Medicina, passa a ser de $40 \%$ da carga horária total do curso ofertado, devendo as Instituições de Ensino Superior ter conceito igual ou superior a três nos indicadores: metodologia, atividades de tutoria, ambiente virtual de aprendizagem e tecnologias de informação e comunicação, quando da autorização, reconhecimento ou renovação de reconhecimento de seus cursos presenciais, sob pena de não ter o curso autorizado, conforme artigo $7^{\circ}, \S 1^{\circ}$ da Portaria $2.117 / 2019$, ou no caso de reconhecimento ou renovação de reconhecimento, gerar protocolo de compromisso para superar as fragilidades detectadas, conforme prevê o artigo 52, inciso II e artigo 53 do Decreto $n^{\circ} 9.235$ de 2017.

Destaca-se que esta possibilidade de ampliação para $40 \%$ é vedada apenas para o curso de Medicina, podendo ser aplicada nos demais cursos de graduação presenciais da área da saúde e também das engenharias, uma vez que a portaria 1.428 de 2018 foi revogada.

Foi possível verificar uma evolução da legislação brasileira para permitir um ensino híbrido, misturado, saindo de uma modalidade $100 \%$ presencial (que ainda existe), admitindo uma modalidade $100 \%$ a distância (que também continua existindo) até chegar em uma modalidade, onde $60 \%$ da carga horária do curso de graduação deve ser presencial e $40 \%$ poderá ser ofertado na modalidade a distância com a possibilidade de aplicação de metodologias e componentes curriculares do ensino híbrido.

\section{Referências}

BACICH, L.; TANZI NETO, A.; TREVISANI, F.M. Ensino Hibrido: personalização e tecnologia na educação. Porto Alegre: Penso, 2017.
BRASIL. Constituição da República Federativa do Brasil de 1988. 1988. Disponível em: http://www.planalto.gov.br/ccivil_03/ Constituicao/Constituicao.htm Acesso em: 10 mar. 2019.

BRASIL. Lei no 9.394 de 1996, de 20 de dezembro de 1996, que estabelece as diretrizes e bases da educação nacional. Disponível em: http://www.planalto.gov.br/ccivil_03/LEIS/L9394.htm Acesso em: 10 mar. 2019.

BRASIL. Decreto ${ }^{\circ}$ 2.494, de 10 de fevereiro de 1998, que regulamenta o Art. 80 da LDB. Disponível em: http://portal.mec. gov.br/seed/arquivos/pdf/tvescola/leis/D2494.pdf Acesso em: 10 mar. 2019.

BRASIL. Decreto ${ }^{\circ} 2.561$, de 27 de abril de 1998 que altera a redação dos arts. 11 e 12 do Decreto $\mathrm{n}^{\circ} 2.494$, de fevereiro de 1998, que regulamenta o disposto no art. 80 da Lei $n^{\circ} 9.394$ de 1996, de 20 de dezembro de 1996. Disponível em: http://portal. mec.gov.br/seed/arquivos/pdf/tvescola/leis/D2561.pdf Acesso em 10 mar. 2019.

BRASIL. Decreto $\mathrm{n}^{\mathrm{o}}$ 5.622, de 19 de dezembro de 2005. 2005. Disponível em: http://www.planalto.gov.br/ccivil 03/ Ato20042006/2005/Decreto/D5622.htm Acesso em: 10 mar. 2019.

BRASIL (2017). Decreto ${ }^{\circ}$ 9.057, de 25 de maio de 2017, que regulamenta o art. 80 da Lei $\mathrm{n}^{\circ} 9.394$, de 20 de dezembro de 1996, que estabelece as diretrizes e bases da educação nacional. Disponível em: http:/www.planalto.gov.br/CCIVIL_03/ Ato2015-2018/2017/Decreto/D9057.htm. Acesso em: 10 mar. 2019.

BRASIL. Portaria do Ministério da Educação $n^{0} 2.253$, de 18 de outubro de 2001. 2001. Disponível em: https://www2.camara. leg.br/legin/marg/portar/2001/portaria-2253-18-outubro-2001412758-norma-me.html Acesso em: 24 abr. 2019.

BRASIL. Portaria do Ministério da Educação no 4.059, de 10 de dezembro de 2004. 2004. Disponível em: http://portal.mec.gov. br/sesu/arquivos/pdf/nova/acs_portaria4059.pdf Acesso em: 24 abr. 2019.

BRASIL. Portaria do Ministério da Educação n ${ }^{\circ} 1.134$, de 10 de outubro de 2016. 2016. Disponível em: http://www.uel.br/ prograd/docentes/documentos/pp/portaria_mec_1134_16.pdf. Acesso em: 24 abr. 2019.

BRASIL. Portaria do Ministério da Educação ${ }^{\circ} 1.428$, de 28 de dezembro de 2018. 2028. Disponível em: http://portal.mec. gov.br/index.php?option=com_docman \&view=download\&a lias=108231-portaria-1428\&category_slug=fevereiro-2019pdf\&Itemid=30192 Acesso em: 24 abr. 2019.

BRASIL. Portaria do Ministério da educação n 343 de 17 de março de 2020. 2020. Disponível em: http://www.planalto.gov. br/CCIVIL_03/Portaria/PRT/Portaria\%20n\%C2\%BA\%2034320-mec.htm Acesso em: 20 abr.2020.

DINIS, E.C. et al. Educação a Distância: coletânea de textos para subsidiar a docência on line. João Pessoa: UFPB, 2011.

PILLON, A.E.; FREITAS FILHO, F.L.; MISAGHI, M. Educação a Distância sob a ótica da satisfação dos alunos. Curitiba: Appris, 2018. 